\title{
CLASH OF CHEMISTS: A GAMIFIED BLOG TO MASTER THE CONCEPT OF LIMITING REAGENT STOICHIOMETRY
}

\author{
Nathalie V. le Maire,,$^{*} \dagger$ Dominique Ph. Verpoorten,,$^{\ddagger}$ Marie-Laure S. Fauconnier, ${ }^{\dagger}$
}

5 Catherine G. Colaux-Castillo ${ }^{\dagger}$

†AGROBIOCHEM, Gembloux AgroBioTech - University of Liège, Passage des Déportés 2, 5030 Gembloux, Belgium

\# Support Laboratory for Telematic Learning (LabSET), University of Liège, Boulevard de Colonster B9, 4000 Liège, Belgium

10 ABSTRACT

In a first-year university course, students experienced a new learning activity ("Clash of Chemists") prompting them to create and share personal analogies explaining the difference between stoichiometric and non-stoichiometric reaction conditions, also known in literature as "limiting reagent stoichiometry". To support students' commitment to this unusual assignment, the instructional design drew on a blog enriched with game mechanics (tournament, video rewards, and leaderboard), as found in popular mini-games. The paper reports on the activity's outputs and on participants' perceptions of its usability, usefulness and generated satisfaction. Overall students' reception of this mini-game was positive. A significant difference between players and non-players' end-of-term exam results was highlighted. 


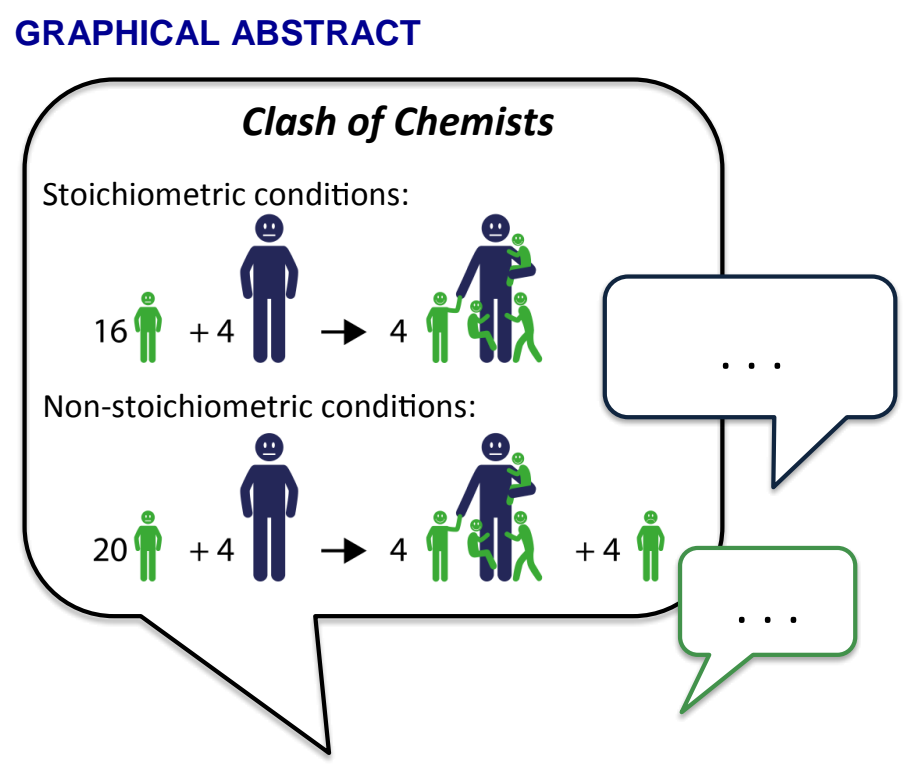

\section{KEYWORDS}

First Year Undergraduate/General, Analogies/Transfer, Collaborative/Cooperative

Learning, Communication/Writing, Internet/Web-Based Learning, Stoichiometry

\section{INTRODUCTION}

In today's society, technology and games have a special place, especially in the lives of children, teenagers, and students. ${ }^{1}$ It is rare to see them not interacting with some kind of technology (e.g., mobile phones, tablets, or personal computers) and they are sometimes portrayed as the "Net Generation", 2 "Homo Zappiens", 3 "Millenials", 4

"Generation Y", ${ }^{5}$ or "Digital natives". ${ }^{6}$ Utilizing their close relationship with these tools and generating educational games seem promising to engage students in learning activities and enhance their understanding of challenging chemistry topics. Among these topics, stoichiometry of reactions is critical when it comes to understanding how reactions work and particularly the difference between stoichiometric and nonstoichiometric reaction conditions, also known in literature as "limiting reagent stoichiometry". In the remainder of the article, the expression "stoichiometric versus non-stoichiometric reaction conditions" will be favored because it is in better agreement with the learning objectives of the mini-game. First year undergraduate students in a 
general chemistry course are expected to balance a chemical equation, to define whether the reaction conditions are stoichiometric or not (the identification of the limiting reagent), and finally to quantify the products and/or the reagents in excess. These routine operations are complex for students for several reasons. In the cognitive realm, they require the use of three levels of knowledge: symbolic, microscopic, and macroscopic, ${ }^{7}$ and knowledge of mathematics, and problem solving skills which students may lack. ${ }^{8}$ It also appears that the chemical vocabulary associated with stoichiometric problems brings a complexity of its own that can prevent students from using simple mathematical operations to solve them. ${ }^{9}$ Frequently pre-conceptions can also be an obstacle: ${ }^{10}$ some students struggle to interpret a chemical equation concerning the ratio in which the reactants react ${ }^{11}$ and have difficulties in understanding that all the available amount of reagents is not necessarily reacting. ${ }^{10}$ Moreover, for some students, an equation implies the use of stoichiometric quantities and the identification of the limiting reagent is a major impediment, often forgotten to be determined, or identified incorrectly (for example, the limiting reagent is the compound with the smallest stoichiometric coefficient in the balanced equation). ${ }^{12}$ Furthermore, it is not obvious for all students that one chemical equation can represent many experimental situations ${ }^{13}$ and it goes against their habits to apply one standardized procedure to solve problems. ${ }^{14}$ This reduction of stoichiometry to mere drill \& practice sequences (an imagery that sometimes dates back to high school) can encourage a shallow understanding of the phenomenon at stake and hamper in-depth understanding. In the affective domain, stoichiometry, as presented in traditional chemistry textbooks, is a phenomenon not related to the students' everyday life. ${ }^{2}$ It is considered by pupils at the end of secondary school to be one of the most difficult concepts of chemistry, ${ }^{15}$ inducing for many of them a lack of motivation due to a lack of self-confidence. This web of recurring difficulties associated, for a large number of 
students, to a central notion (and possibly a "threshold concept" ${ }^{16,17)}$ in chemistry is therefore worth devoting specific pedagogical efforts to, as is done with the proposed activity "Clash of Chemists".

One traditional method to support students' mastery of the challenging notion of the difference between stoichiometric and non-stoichiometric reaction conditions is "illustrated analogies". ${ }^{9}$ It is recommended because it provides "a bridge between an unfamiliar concept and the knowledge that students possess". ${ }^{18}$ Among others, the book of general chemistry ${ }^{19}$ used by bioengineering students at the University of Liège (Belgium) uses this process (see Figure 1).

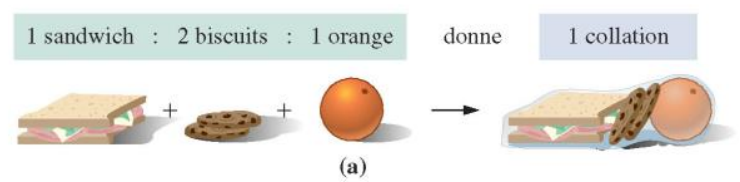

(a)

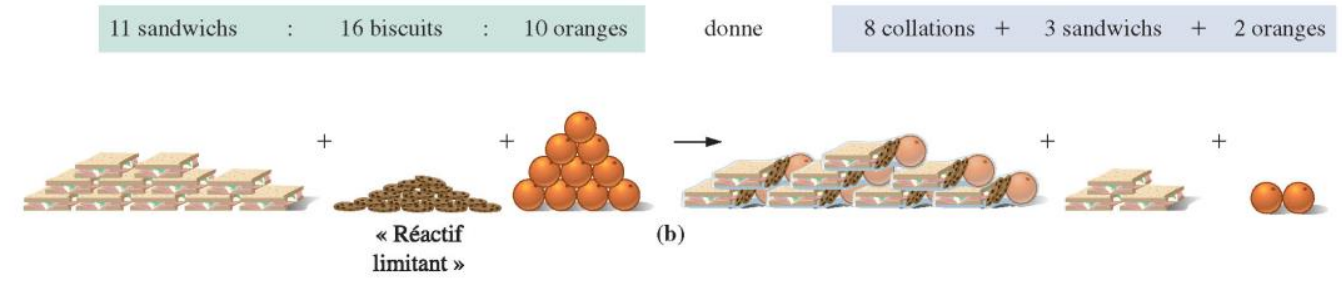

Figure 1. Stoichiometry analogy. (a) 1 sandwich, 2 cookies, and 1 orange make up 1 snack. (b) 11 sandwiches, 16 cookies, and 10 oranges make up 8 snacks with 3 sandwiches and 2 oranges remaining; cookies are the "limiting reagent". Reprinted with permission from ref 19. Copyright 2008 Pearson-ERPI. motivating students by stimulating students' interest, facilitating visualization of abstract concepts by comparisons with concrete objects in the real world, and promoting the creation of new analogies. However, the use of a single analogy by one teacher or one textbook can impede its potential benefit for learners if they are not familiar with the domain of analogy, or have a misleading experience with it. ${ }^{20}$ The learning process might therefore benefit from the creation of multiple analogies devised by students themselves. ${ }^{21}$ The potential of such an approach is threefold: a) it results in 
an extended repertoire of analogies to choose and contrast, b) it provides a moment for an active and creative assignment (a different type of learning event ${ }^{22}$ ) in a course of chemistry mostly rooted in lectures and practicums, c) it uses a tool that facilitates peer interactions (using a blog), ${ }^{23}$ and gamification, defined as the "the use of game design elements in non-game contexts", ${ }^{24}$ creating an opportunity to introduce technologyenhanced social learning, meant to promote motivation, ${ }^{25}$ increase performance, and self-efficacy. ${ }^{26}$

Based on these premises, the team of teachers chose a learning activity design called "Clash of Chemists" in reference to the popular mini-game "Clash of Clans" which partly served as an inspiration. This activity was intended to provide students with an unconventional opportunity to train and consolidate their understanding of the difference between stoichiometric and non-stoichiometric reaction conditions, to try a gamified activity $27-29$ in the course, and to contribute to the diversification of learning methods. 22

\section{MATERIALS AND METHODS}

Student population and course "Clash of Chemists" was proposed to 223 first year undergraduate students at chemistry. Participation in the game-based approach was optional and not required to pass the course which represents 7 ECTS credits (European Credit Transfer and Accumulation System) of the 60 that compose a one-year program.

The game was available for two weeks between the lesson on stoichiometry and the end-of-term exam.

The mini-game

The game "Clash of Chemists" was implemented in the institutional Learning Management System that students were familiar with (Blackboard Learn ${ }^{30}$ ) and it exploited its tool "Blog". 
The homepage of the blog reminds students of the analogy proposed in their textbook (see Figure 1) and describes the rules of the game. The mini-game has 3 steps (screenshots of the main steps from the game are available in supporting information) allowing players to earn or lose points to generate a leaderboard (a "high-score table" displaying competitive results and celebrating winners ${ }^{31}$ ).

First step: players are invited to create their own analogy, representing the difference between stoichiometric and a non-stoichiometric reaction conditions by submitting a post to the blog. The post can be text and/or an illustration.

Second step: players can view other players' analogies and if they consider them to be incorrect, they can suggest contradictory comments and arguments.

Final step: "attacked" players have the opportunity to defend themselves by proposing a correction of their analogy.

In order to populate and update a leaderboard displayed on Blackboard Learn, the blog is monitored by a teaching assistant who evaluates the relevance of the three steps, based on four criteria: a) presentation of two distinct situations, b) organization of items (on the left) that can give other items (on the right), c) notion of amounts that vary from one situation to the other, d) identification of the limiting and excess reagents in the second situation. Each action allows players to earn or lose points (Table 1) that are counted by the teaching assistant to generate rankings. In this way, students can have an idea of the correctness of their proposal by seeing whether their score is credited with additional points. The final goal of the mini-game is to collect as many points as possible by actively participating in each of these three steps to rise to the top of the rankings. 
Table 1. Each action of the game allows participants to earn or to lose points for the leaderboard

\begin{tabular}{clc} 
Step & Actions & Points \\
1 & Create a correct analogy & +5 \\
\hline \multirow{2}{*}{2} & Attack the incorrect analogy of another player & +3 \\
\cline { 2 - 3 } & Be attacked by another player & -1 \\
\hline 3 & Defend against attack using scientific argument & +2 \\
\hline
\end{tabular}

Beside the intrinsic motivation targeted by the ranking and the tournament, extrinsic motivation ${ }^{32}$ was provided in the form of a video reward. Any participation (creation, attack, or defense) in the blog unlocked access to a single video of an expert (the teacher) explaining how to solve an exam problem about stoichiometry of reactions.

\section{Data sources}

At the end of the game, an anonymous survey was administered to students (players and non-players) to collect their opinions about this approach. The non-players were asked to give the reasons why they did not play, while several questions were asked to players concerning the usability and the usefulness of the game, along with their satisfaction. The different items were evaluated on a Likert-type scale from 1 to 5 respectively representing the lowest and highest degree to which respondents agree with the items. The participants were also asked to list the strong and weak points of this analogy-based gamified set-up. The survey was available online on Blackboard Learn.

In order to investigate the performance of players at a stoichiometry question of the end-of-term exam in comparison to non-players, an ANOVA was performed comparing the marks obtained on 12 points.

\section{RESULTS}

Student participation

Of 223 registered students for the general chemistry course, 107 took part in Clash of Chemists, i.e. 48\%. Among these students, 106 proposed at least one analogy, 12 
attacked at least one other player, 16 were attacked and 2 corrected their incorrect posts. In total, 114 different analogies were created by the players ( 8 players proposed two analogies).

\section{Student creations}

Observation of students' analogies reveals the creativity of many players. Moreover, eight of them took time to illustrate their proposal. "Recipes" category was the most popular category with 39 instances, the majority of which were contextualized in a pizza party, preparing snacks, moving in, or Candlemas, a Christian festival. For instance, a student described a situation where she wanted to prepare 20 Mojitos for a party but that she lacked 2 limes. She then asked her friend, Pauline, to bring her two. Two situations were then possible: either her friend brought two limes (stoichiometric conditions) or her friend forgot them (non-stoichiometric conditions) (see Figure 2).

Situation 1: Pauline brings the 2 limes

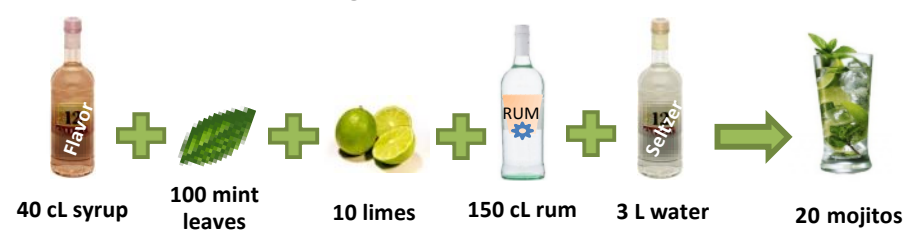

\section{Situation 2: Pauline forgets the 2 limes}

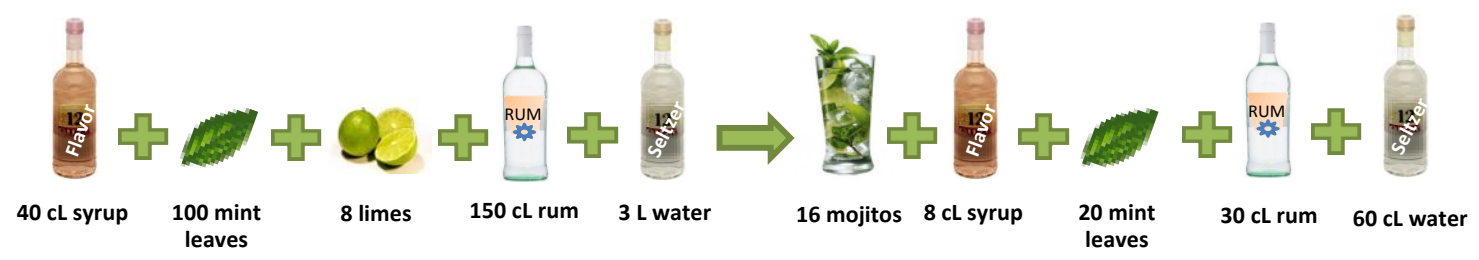

Figure 2. Mojito analogy proposed by a student. Adapted with permission from the student.

Another popular category was proposals that draw on the assembly of different items, such as a car, table, house, tank, stool, or even a traditional wheelbarrow wellknown in the folklore of the faculty. A student was also inventive and proposed a 
comparison with the appropriate number of boy-scouts that can be supervised by one organizer (see Figure 3).

\section{Stoichiometric conditions:}

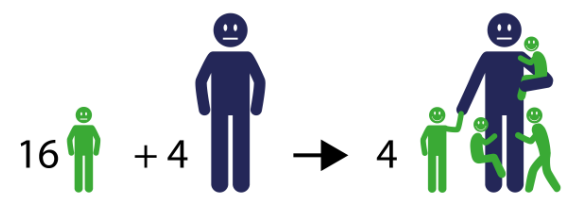

\section{Non-stoichiometric conditions:}

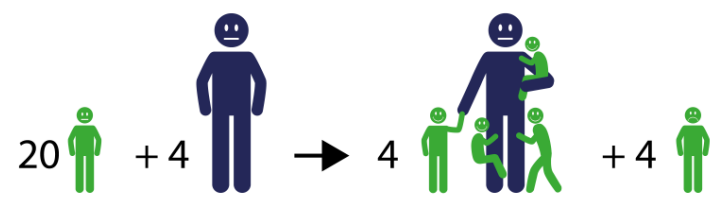

Figure 3. Boy-scout analogy proposed by a student. Adapted with the permission from the student.

Use of the video reward

Among the 107 players who received access to the video reward, 41 watched it within the two weeks after the game, five watched it again before the end-term exam and three watched it before the second exam session.

Evaluation of Clash of Chemists by students

A total of 53 students (41 players/12 non-players) answered the anonymous survey.

Usability and Usefulness: Players' evaluation of the usability of the gamified blog shows that $65 \%$ of respondents agree or strongly agree that the system was easy to use and $49 \%$ consider that playing this game was useful to improve their understanding, against $31 \%$ who do not (see Figure 4).

I think that the system was easy to use

I think that playing this game was useful to improve my understanding
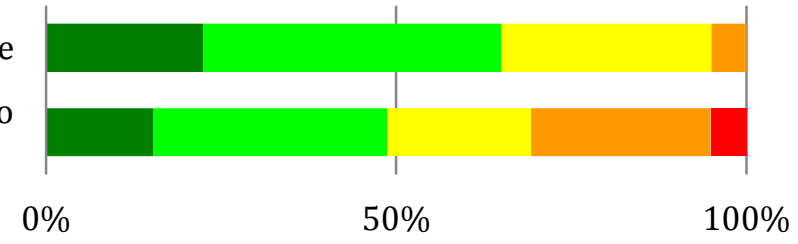

$\square$ Strongly agree $\square$ Agree $\square$ Neutral $\square$ Disagree $\square$ Strongly disagree

Figure 4. Clash of Chemists was overall perceived by students as usable and useful $(n=41)$. 
Satisfaction: $55 \%$ of respondent players liked playing the mini-games and $92.5 \%$ intend to play the next potential mini-games proposed in the course. Moreover, $60 \%$ would advise other students to play. Only $12.5 \%$ of respondent players did not enjoy playing the mini-game and did not find it complementary to the other course materials. $15 \%$ would not like to use this kind of approach more often and only $17.5 \%$ would have preferred to study from their lecture book (see Figure 5).

I enjoyed playing the mini-game

I find that this mini-game and the other course materials are complementary

I would like to use this kind of mini-game more often

I intend to play the next proposed mini-games of the course

I would advise students who did not play to do so

I would have preferred to use the time to study my syllabus rather than playing the mini-game

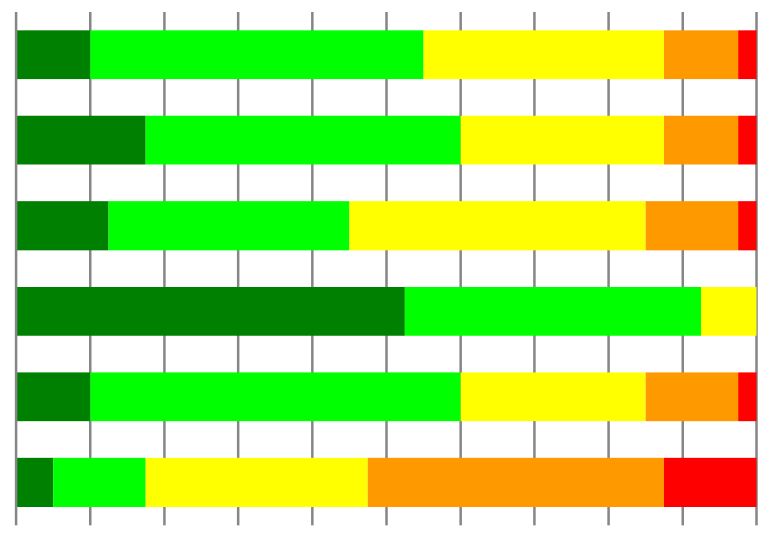

0\% 10\% 20\% 30\% 40\% 50\% 60\% 70\% 80\% 90\%100\%

$\square$ Strongly agree $\square$ Agree $\square$ Neutral $\square$ Disagree $\square$ Strongly disagree

Figure 5: Most students have positive perceptions of Clash of Chemists $(n=41)$.

Perception of video reward: Among the 38 players who answered the two questions about the video reward, $58 \%$ considered that the explanations given in the video were clear and only $10 \%$ don't think that the video reward allowed them to improve their understanding (see Figure 6). 
The video reward allowed me to improve my understanding

The explanations given in the video were clear

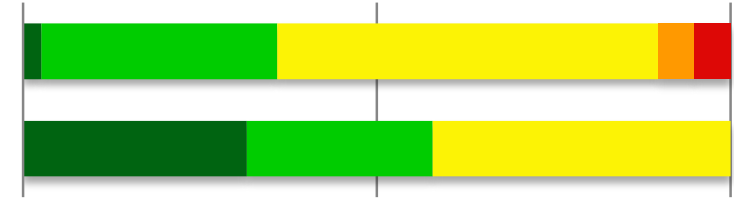

$\begin{array}{lll}0 \% & 50 \% & 100 \%\end{array}$

$\square$ Strongly agree $\quad$ Agree $\quad$ Neutral $\quad$ Disagree $\square$ Strongly disagree

Figure 6: Most students have positive perception of the video reward $(n=38)$.

Strengths and weaknesses: Additionally, students were asked about strong and weak points of this gamified approach. Among the 33 positive comments, the most important aspects were that the game is helpful to understand the target concept $(30 \%)$, it encourages reflection (18\%), it allows a concrete representation or visualization of an abstract concept (18\%) and is enjoyable (18\%). The 28 negative comments were mainly about the competition (21\%), the usability of the blog (18\%), the long thinking time $(14 \%)$ and the creativity $(14 \%)$ needed.

Non-player reasons: The 12 non-player respondents mentioned several reasons to explain their non-participation of Clash of Chemists, among which a lack of time (33\%) and forgetting $(17 \%)$ were the most cited.

Effect on student performance: The ANOVA analysis (Table 2) shows a significant difference $(p=.007)$ between end-of-term exam results of players and non-players at a stoichiometry question.

Table 2. Comparative End-of-Term Exam Performance

\begin{tabular}{|c|c|c|c|}
\hline Student group & $\mathrm{M}^{\mathrm{a}}$ & $\mathrm{SD}$ & ANOVA Results \\
\hline Players $(n=105)$ & 7.4 & 4.7 & $\begin{array}{c}F(1,208)=7.31 \\
p=.007\end{array}$ \\
\hline Non-players $(\mathrm{n}=105)$ & 5.6 & 4.7 & $\eta_{\mathrm{p}}^{2}=.0173$ \\
\hline
\end{tabular}


The aim of Clash of Chemists was to encourage students to develop a visual and imaginative approach to the stoichiometry of reactions by creating their own analogy, grounded in a comparison that made sense to them. Beside the advantages in terms of soft skills such as the use of a communication tool, a blog, and the practice of argumentation; the proposed mini-game, Clash of Chemists, allowed students to assimilate the difference between stoichiometric and non-stoichiometric reaction conditions. In order to create a relevant personal analogy linked to their everyday life expressing the mastery of the concept of excess and limiting reagents, students first had to go over their previous misconceptions and integrate the fact that a chemical equation doesn't necessarily imply the use of proper stoichiometric quantities. Moreover, the reading of other students' analogies triggered multiple comparisons between their understanding of the concept and other representations of it, offering opportunities to overcome any misconceptions especially due to the use of a unique analogy ${ }^{33}$ and allowing them to understand that one chemical equation can represent many experimental situations.

The participation rate of about $50 \%$ for an optional activity and the multiple analogies proposed are encouraging and indicate curiosity and motivation of students for an unusual type of exercise. The triangulation of correct analogies and students' comments about strong and weak points of this gamified approach provides clear indications that this extra activity contributed to an enhanced understanding of the concept of stoichiometry of reactions and to deal with the idea of limiting and excess reagents, especially by encouraging the creation of concrete representations. Furthermore, the ANOVA analysis highlighted a higher performance by the players on the question about the targeted concept at the end-of-term exam. Even if the starting level of the students is not known, we can reasonably infer, based on litterature, ${ }^{26,34}$ that the game had some contribution to improving understanding of the concept. 
Overall, students seem to have appreciated the gamified approach and they intend to play the next games that could be proposed in the course. This agrees with the fact that using and creating analogies to understand abstract concepts increases enjoyment and interest. ${ }^{35}$ In their comments about the strong and weak points of the gamified blog, several students mentioned the rankings as a negative aspect of the mini-game. For some students, leaderboards can be a source of motivation that increases engagement in the activity, ${ }^{36}$ while for others competition can be discouraging. ${ }^{37}$ In the present approach the competition was used moderately and should not have had negative consequences as the leaderboard had no impact on academic success, as recommended by Glover. ${ }^{37}$ Moreover, the competition was combined with a cooperative aspect as feedback was given by other students.

Three limitations can be highlighted and could be an inspiration for further works. Firstly, we are not able to know if one part of the mini-game has a major impact on the understanding of students. All the steps (creation, attack, defense, reading other analogies, reward) shaped the mini-game that allowed those results to be obtained. Secondly, the teaching assistant had only a passive role of counting points in order to generate the leaderboard, but did not interact with students to provide feedback. It could have been interesting to use several analogies by students in class to debrief about the mini-game. Lastly, it could have been interesting to compare the ANOVA results obtained for the same students' performances on different topics for the end-ofterm exam results in order to consolidate the observed differences between players and non-players. Unfortunately, it was not relevant because all topics on the same end-ofterm exam had also some kind of enhanced learning (for example, other types of games) or dealt with stoichiometry of reactions, which can be defined as a core concept in the learning of chemistry. 
Lastly, it would be worthwhile to apply the same approach to other chemistry concepts (dilution or moles) or other scientific subjects and to see whether the positive aspects identified in this study are likely to transfer (notes for instructors are available in supporting information). However, this kind of tool needs to be monitored by the teacher and could not easily be automated. An investment by the teacher is therefore required, but paid off by the enjoyment of reading students' propositions.

\section{ASSOCIATED CONTENT}

Supporting Information

Notes for instructors and screenshots of the main steps from the game are available.

\section{AUTHOR INFORMATION}

Corresponding Author

*E-mail: nlemaire@uliege.ac.be

\section{ACKNOWLEDGMENTS}

We acknowledge the participation of students from Gembloux Agro-Bio Tech who tested the game and gave a favorable feedback and we particularly thank the two students who consent to the adaptation of their analogies. We also thank Georges Lognay (Gembloux Agro-Bio Tech, University of Liège) and Steve Lanners (Department of Chemistry, University of Namur) for proofreading as well as Jérémy Dehon (Departement of Chemistry, University of Namur) for his help from a didactic point of view.

\section{REFERENCES}

1. Prensky, M. Teaching Digital Natives: Partnering for Real Learning; Corwin: Thousand Oaks, CA, 2012.

2. Oblinger, D. G., Oblinger, J. L.; Eds. Educating the Net Generation, Educational Leadership (Vol. 56); Educause: Louisville, CO, 2005;

https://www.educause.edu/ir/library/pdf/pub7101m.pdf (accessed Dec 2017). 
3. Veen, W., \& Vrakking, B. (2006). Homo Zappiens: Growing up in a digital age. London, UK: Network Continuum Education.

4. Stein, J. Millennials: The me me me generation. Time Magazine, May 20, 2013. http://time.com/247/millennials-the-me-me-me-generation/?iid=sr-link1 (accessed Dec 2017).

5. Weiler, A. (2004). Information-seeking behavior in generation Y students: Motivation, critical thinking, and learning theory. The Journal of Academic Librarianship, 31(1), 46-53. https://doi.org/10.1016/j.acalib.2004.09.009

6. Prensky, M. (2001). Digital natives, digital immigrants. On the Horizon, 9(5), 1-6. https://doi.org/10.1108/10748120110424816

7. Gabel, D. L. Use of the Particle Nature of Matter in Developing Conceptual Understanding. J. Chem. Educ. 1993, 70 (3), 193-194 DOI: 10.1021/ed070p193.

8. Coll, R. K.; Ali, S.; Bonato, J.; Rohindra, D. Investigating First-Year Chemistry Learning Difficulties in the South Pacific: A Case Study from Fiji. Int. J. Sci. Math. Educ. 2006, 4 (3), 365-390 DOI: 10.1007/s10763-005-9007-6.

9. Haim, L.; Cortón, E.; Kocmur, S.; Galagovsky, L. Learning Stoichiometry with Hamburger Sandwiches. J. Chem. Educ. 2003, 80 (9), 1021-1022 DOI: 10.1021/ed080p1021.

10. Gauchon, L.; Méheut, M. Learning about Stoichiometry: From Students' Preconceptions to the Concept of Limiting Reactant. Chem. Educ. Res. Pract. 2007, 8 (4), 362 DOI: 10.1039/b7rp90012k.

11. Abraham, M. R.; Grzybowski, E. B.; Renner, J. W.; Marek, E. A. Understandings and Misunderstandings of Eighth Graders of Five Chemistry Concepts Found in Textbooks. J. Res. Sci. Teach. 1992, 29 (2), 105-120 DOI: https://doi.org/10.1002/tea.3660290203.

12. Huddle, P. A.; Pillay, A. E. An in-Depth Study of Misconceptions in Stoichiometry and Chemical Equilibrium at a South African University. J. Res. Sci. Teach. 1996, 33 (1), 65-77 DOI: 10.1002/(SICI) 1098-2736(199601)33:1<65::AIDTEA4>3.0.CO;2-N.

13. Laugier, A.; Dumon, A. Travaux Pratiques En Chimie et Réprésentation de La Réaction Chimique Par L'équation-Bilan Dans Les Registres Macroscopique et Microscopique: Une Étude En Classe de Seconde (15-16 Ans). Chem. Educ. Res. Pract. Eur. 2000, 1 (1), 61-75 DOI: https://doi.org/10.1039/a9rp90007a.

14. Goodstein, M. P. Reflections upon Mathematics in the Introductory Chemistry Course. J. Chem. Educ. 1983, 60 (8), 665-667 DOI: 10.1021/ed060p665. 
15. Sheehan, M. Identification of Difficult Topics in the Teaching and Learning of Chemistry in Irish Schools and the Development of an Intervention Programme to Target Some of These Difficulties. PhD thesis, University of Limerick, Limerick, Ireland, 2010. https://chemistrynetwork.pixelonline.org/SMO_database_scheda.php?art_id=21 (accessed Dec 2017).

16. Talanquer, V. Threshold Concepts in Chemistry: The Critical Role of Implicit Schemas. J. Chem. Educ. 2015, 92, 3-9 DOI: 10.1021/ed500679k.

17. Cousin, G. An Introduction to Threshold Concepts. Planet 2006, No. 17, 4-5 DOI: https://doi.org/10.11120/plan.2006.00170004.

18. Gafoor, K. A.; Shilna, V. Chemistry Instruction through Analogies. Presented at the National Seminar on Emerging Trends in Education at the Department of Education, University of Calicut, Kerala, November 11-12, 2012.

https://sites.google.com/site/gafooredn/home/seminars/chemistry-instructionthrough-analogies (accessed Dec 2017).

19. Hill, J. W.; Petrucci, R. H.; McCreary, T. W.; Perry, S. S. Chimie Générale; Mayer, P., Translator; Editions du Renouveau Pédagogique Inc.: Montréal, Canada, 2008.

20. Duit, R. On the Role of Analogies and Metaphors in Learning Science. Sci. Educ. 1991, 75 (6), 649-672 DOI: 10.1002/sce.3730750606.

21. Brown, D. E.; Clement, J. Overcoming Misconceptions via Analogical Reasoning: Abstract Transfer versus Explanatory Model Construction. Instr. Sci. 1989, 18 (4), 237-261 DOI: 10.1007/BF00118013.

22. Verpoorten, D.; Poumay, M.; Leclercq, D. The Eight Learning Events Model: A Pedagogic Conceptual Tool Supporting Diversification of Learning Methods. Interact. Learn. Environ. 2007, 15 (2), 151-160 DOI: 10.1080/10494820701343694.

23. Leslie, P.; Murphy, E. Post-Secondary Students' Purposes for Blogging. Int. Rev. Res. Open Distance Learn. 2008, 9 (3) DOI: 10.19173/irrodl.v9i3.560.

24. Deterding, S.; Sicart, M.; Nacke, L.; O’Hara, K.; Dixon, D. Gamification. Using Game-Design Elements in Non-Gaming Contexts. Proc. 2011 Annu. Conf. Ext. Abstr. Hum. factors Comput. Syst. - CHI EA '11 2011, 2425-2428 DOI: 10.1145/1979742.1979575.

25. Järvelä, S.; Volet, S. Motivation in Real-Life, Dynamic, and Interactive Learning Environments: Stretching Constructs and Methodologies. Eur. Psychol. 2004, 9 (4), 193-197 DOI: 10.1027/1016-9040.9.4.193. 
26. Sung, H.-Y.; Hwang, G.-J. A Collaborative Game-Based Learning Approach to Improving Students' Learning Performance in Science Courses. Comput. Educ. 2013, 63, 43-51 DOI: 10.1016/j.compedu.2012.11.019.

27. Egenfeldt-Nielsen, S. Overview of Research on the Educational Use of Video Games. Digit. Kompet. 2006, 1, 184-213 DOI: 10.1353/dia.2006.0003.

28. McFarlane, A.; Sparrowhawk, A.; Heald, Y. Report on the Educational Use of Games; TEEM/DfES : Cambridge, UK, 2002. http:/ /questgarden.com/84/74/3/091102061307/files/teem_gamesined_full.pdf (accessed Dec 2017).

29. Mitchell, A.; Savill-Smith, C. The Use of Computer and Video Games for Learning: A Review of the Literature; Learning and skills development agency: London, UK, 2004.

30. Blackboard home page. http://uk.blackboard.com/about-us/index.aspx (accessed Dec 2017)

31. Bunchball Inc. Gamification 101: An Introduction to the Use of Game Dynamics to Influence Behavior; 2010. Retrieved from http://bunchball.com

32. Ryan, R.; Deci, E. Intrinsic and Extrinsic Motivations: Classic Definitions and New Directions. Contemp. Educ. Psychol. 2000, 25 (1), 54-67 DOI: 10.1006/ceps. 1999.1020.

33. Spiro, R. J.; Feltovich, P. J.; Coulson, R. L.; Anderson, D. K. Multiple Analogies for Complex Concepts; Antidotes for Analogy-Induced Misconception in Advanced Knowledge Acquisition. In Similarity and analogical reasoning; Vosniadou, S., Ortony, A., Eds.; Cambridge University Press: Cambridge, UK, 1989; pp 498-531.

34. Burguillo, J. C. Using game theory and competition-based learning to stimulate student motivation and performance. Comput. Educ. 2010, 55 (2), 566-575 DOI: https://doi.org/10.1016/j.compedu.2010.02.018

35. Lerman, Z. M. Using the Arts To Make Chemistry Accessible to Everybody. J. Chem. Educ. 2003, 80 (11), 1234-1242 DOI: https://doi.org/10.1021/ed080p1234.

36. Muntean, C. I. Raising Engagement in E-Learning through Gamification. In Proceedings of the 6th International Conference on Virtual Learning; Vlada, M., Ed.; editura universitatii din bucuresti: Bucharest, Roumanie, 2011; pp 323-329.

37. Glover, I. Play as You Learn: Gamification as a Technique for Motivating Learners. In Proceedings of World Conference on Educational Multimedia, Hypermedia and 
Telemcommunications; Herrington, J., Couros, A., Irvine, V., Eds.; Chesapeake, VA, 2013; pp 1998-2008. 